\title{
Usulan Perbaikan Sistem Manajemen Keselamatan dan Kesehatan Kerja (SMK3) sebagai Upaya Meminimalisir Angka Kecelakaan Kerja Menggunakan Metode HAZOP (Studi Kasus: PT. XYZ)
}

\author{
Muhammad Nur',Afriani Putri ${ }^{2}$ \\ 1,2 Jurusan Teknik Industri, Sains dan Teknologi, Universitas Islam Negeri Sultan Syarif Kasim Riau, Pekanbaru. \\ Email: muhammad.nur@uin-suska.ac.id
}

\begin{abstract}
PT. XYZ is a company engaged in oil palm plantations and processing with its main commodity is the oil palm plantations (Elais Queineensis Jack). In 2018, there are several occupational safety and health problems namely occupational accidents experienced by special employees in the production process area. The purpose of this study is to determine the types of work accidents, the types of hazards created based on the risk matrix. This study begins by identifying Hazard and risks and then looking for potential sources of occupational hazard so that harm can be done using the Hazard and Operability Study (HAZOP) method. The research results have been carried out based on the process (Crude Palm Oil) found 8 sources of potential danger between: Loading Ramp Station, Sterilizer Station, Tippler Station, DigesterStation, Press Station, Clarification Station, Kernel Stationdan Boiler Station, then risk assessment: low risk, medium risk, high risk, and extreme risk.
\end{abstract}

Keywords: HAZOP, work accident, risk level

\begin{abstract}
Abstrak
PT. XYZ adalah sebuah perusahaan yang bergerak di bidang perkebunan dan pengolahan kelapa sawit, dengan komoditi utamanya adalah Tanaman Kelapa Sawit (Elais Queineensis Jack). Pada tahun 2018, terjadi beberapa permasalahan keselamatan dan kesehatan kerja yaitu kecelakaan kerja yang dialami oleh karyawan khususnya pada area proses produksi. Tujuan dari penelitian ini adalah untuk mengetahui jenis kecelakaan kerja, jenis resiko bahaya yang ditimbulkan berdasarkan Matrik Resiko (Risk Matrix). Penelitian ini diawali dengan melakukan identifikasi hazard and risk dan selanjutnya mencari sumber potensi bahaya kecelakaan kerja sehingga dapat dilakukan pencegahan kecelakaan dengan menggunakan metode Hazard and Operability Study (HAZOP). Hasil penelitian yang telah dilakukan berdasarkan proses dari identifikasi bahaya pada proses produksi pembuatan CPO (Crude Palm Oil) ditemukan 8 sumber potensi bahaya, diantaranya: Staiun Loading Ramp, Stasiun Sterilizer, Stasiun Tippler (Pembanting), Stasiun Digester, Stasiun Press, Stasiun Klarifikasi, Stasiun Kernel dan Stasiun Boiler, kemudian penilaian risiko: resiko rendah, resiko sedang, resiko tinggi dan resiko ekstrim.
\end{abstract}

Kata kunci: HAZOP, kecelakaan kerja, risk level

\section{Pendahuluan}

Pembangunan nasional sedang memasuki era industrialisasi dan globalisasi yang ditandai dengan semakin berkembangnya perindustrian. Sehingga diperlukan peningkatan kualitas sumber daya manusia serta pelaksanaan yang konsisten dari Sistem Manajemen Keselamatan dan Kesehatan Kerja (SMK3). Keselamatan dan kesehatan kerja atau K3 merupakan hal yang tidak terpisahkan dalam sistem ketenagakerjaan dan sumber daya manusia. Keselamatan dan kesehatan kerja tidak hanya sangat penting dalam meningkatkan jaminan sosial dan kesejahteraan para pekerjanya akan tetapi jauh dari itu keselamatan dan kesehatan kerja berdampak positif atas keberlanjutan produktivitas kerjanya. Oleh sebab itu keselamatan dan kesehatan kerja pada saat ini bukan sekedar kewajiban yang harus diperhatikan oleh para pekerja, akan tetapi juga harus dipenuhi oleh sebuah sistem pekerjaan karena sudah merupakan sebuah kebutuhan yang harus terpenuhi bagi setiap pekerja (Rudyarti, 2017). 
Usulan Perbaikan Sistem Manajemen Keselamatan dan Kesehatan Kerja (SMK3) sebagai Upaya Meminimalisir Angka Kecelakaan Kerja Menggunakan Metode HAZOP (Studi Kasus: PT. XYZ)

PT. XYZ adalah sebuah perusahaan yang bergerak dibidang perkebunan dan pengolahan kelapa sawit, dengan komoditi utamanya adalah Tanaman Kelapa Sawit (Elais Queineensis Jack). PT. XYZ telah menerapkan Sistem Manajemen Keselamatan dan Kesehatan Kerja (SMK3). Program K3 tersebut dilakukan guna menunjang keselamatan tenaga kerja. Selain itu terdapat juga Standard Operating Procedure (SOP) pada setiap jenis pekerjaan yang bertujuan agar pekerja dapat bekerja sesuai dengan standar. Meskipun PT. XYZ sudah menerapkan program K3 secara rutin dan SOP pada setiap jenis pekerjaan, namun kecelakaan kerja masih terjadi setiap tahunya.

Pengetahuan pekerja PT. XYZ menganai K3 masih sangat kurang, walaupun dari pengakuan pekerja pernah mengikuti pelatihan ataupun ceramah tentang K3.Selain itu dalam pemakaian Alat Pelindung Diri (APD) pada saat bekerja masih belum maksimal.Pada kenyataannya masih banyak juga pekerja yang tidak menggunakannya APD walaupun telah diketahui besarnya manfaat alat ini dan perusahaan sudah menyediakan alat pelindung diri.

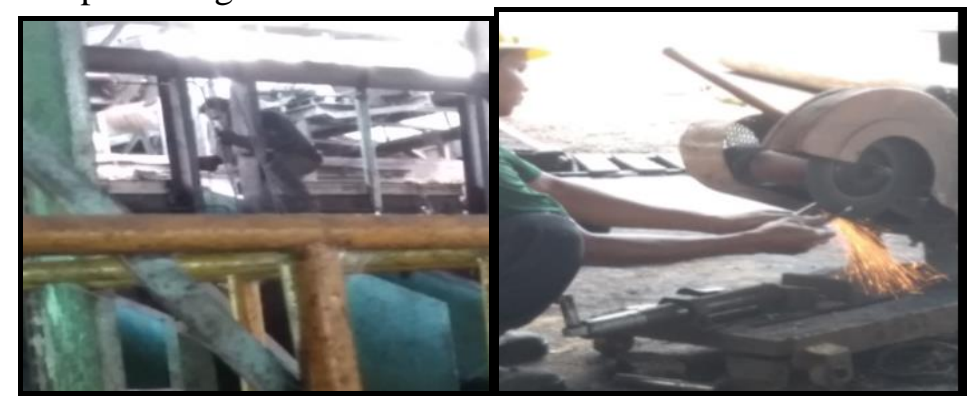

Gambar 1: Pekerja Tidak Menggunakan Alat Pelindung Diri (APD)

(Sumber: PT. XYZ, 2018)

Kecelakaan kerja adalah suatu kejadian yang tidak dikehendaki yang dapat menimbulkan kerugian baik secara materi dan non materi (Nuraini dan Ratih, 2015). Kecelakaan kerja dapat disebabkan oleh beberapa faktor yaitu (Hutasoit, 2011 dikutip oleh Nur dan Chania, 2016) faktor manusia, faktor peralatan kerja, dan faktor dari lingkungan kerja.

Kecelakaan kerja berhubungan dengan hubungan kerja di perusahaan.Hubungan kerja dalam hal ini adalah kecelakaan kerja yang terjadi disebabkan oleh karyawan itu atau kesalahan dalam peralatan yang digunakan oleh karyawan pada waktu melaksanakan pekerjaan (Nur dan Al, 2015). Berikut data kecelakaan kerja pada lantai produksi Tahun 2018 di PT. XYZ.

Tabel 1: Data Kecelakaan Kerja Pada Lantai Produksi Tahun 2018

\begin{tabular}{ccc}
\hline Bulan & Jumlah Kecelakaan Kerja & Jenis Kecelakaan Kerja \\
\hline Januari & - & - \\
\hline Febuari & 1 & Ringan \\
\hline Maret & 1 & Ringan \\
\hline April & - & - \\
\hline Mei & 1 & Ringan \\
\hline Juni & - & - \\
\hline Juli & 1 & Ringan \\
\hline Agustus & 2 & Berat \\
\hline September & 1 & Ringan \\
\hline Oktober & 1 & Ringan \\
\hline November & - & - \\
\hline Desember & 1 & Berat \\
\hline Total & 9 & \\
\hline
\end{tabular}

(Sumber: PT. XYZ, 2018) 
Usulan Perbaikan Sistem Manajemen Keselamatan dan Kesehatan Kerja (SMK3) sebagai Upaya Meminimalisir Angka Kecelakaan Kerja Menggunakan Metode HAZOP (Studi Kasus: PT. XYZ)

Dari data kecelakaan kerja yang telah dilihat tentu berdampak negatif terhadap perusahaan baik dari target produksi maupun dari segi biaya pengeluaran yang harus di tanggung oleh perusahaan. Berikut ini adalah data Target Produksi yang dapat dilihat pada Tabel 2:

Tabel 2: Data Target Produksi PT. XYZ Tahun 2018

\begin{tabular}{cccc}
\hline Bulan & $\begin{array}{c}\text { Target Produksi/Bulan } \\
\text { (Ton) }\end{array}$ & $\begin{array}{c}\text { Jumlah } \\
\text { Produksi/Bulan } \\
\text { (Ton) }\end{array}$ & Keterangan \\
\hline Januari & 30.960 & 31.892 & Tercapai \\
\hline Febuari & 30.947 & 27.524 & Tidak Tercapai \\
\hline Maret & 32.977 & 20.998 & Tidak Tercapai \\
\hline April & 33.947 & 20.950 & Tidak Tercapai \\
\hline Mei & 36.584 & 29.300 & Tidak Tercapai \\
\hline Juni & 34.473 & 24.707 & Tidak Tercapai \\
\hline Juli & 35.459 & 25.026 & Tidak Tercapai \\
\hline Agustus & 36.814 & 19.286 & Tidak Tercapai \\
\hline September & 36.834 & 24.886 & Tidak Tercapai \\
\hline Oktober & 36.893 & 25.330 & Tidak Tercapai \\
\hline November & 36.789 & 24.276 & Tidak Tercapai \\
\hline Desember & 35.257 & 28.877 & Tidak Tercapai \\
\hline Total & $\mathbf{4 1 7 . 9 3 4}$ & $\mathbf{3 0 3 . 0 5 2}$ & \\
\hline
\end{tabular}

(Sumber: PT. XYZ, 2018)

Berdasarkan Tabel 2 menunjukan target produksi CPO (Crude Palm Oil) yang ada pada PT. XYZ dari bulan Januari-Desember Tahun 2018, menurut hasil wawancara dengan asisten proses produksi, target produksi dalam perbulan mengalami perubahan, biasannya target produksi tidak tercapai karena disebabkan oleh berbagai faktor seperti buah sawit yang diproduksi tidak mencukupi target, pekerja harus cuti dalam beberapa bulan atau beberapa minggu serta akibat dari kecelakaan kerja. Dari data target produksi yang ada pada Tabel 2 dapat dilihat bahwa dari bulan Januari-Desember jumlah produksi yang ada di PT. Sari Lembah Subur tidak dapat memenuhi target produksi. seperti yang terlihat pada bulan Agustus hanya mampu memproduksi sebanyak 19.286 Ton CPO, dikarekan adannya 2 kasus kecelakaan kerja.

Berdasarkan data yang didapatkan, berikut adalah biaya yang di tanggung oleh PT. XYZdalam menangani kasus kecelakaan kerja dalam tahun 2018.

Tabel 3: Data Biaya Kecelakaan Kerja PT. XYZ2018

\begin{tabular}{ccc}
\hline Bulan & Biaya Kecelakaan Kerja & Jumlah Kasus \\
\hline Januari & - & - \\
\hline Febuari & $35.000,00$ & 1 \\
\hline Maret & $21.000,00$ & 1 \\
\hline April & - & - \\
\hline Mei & $20.500,00$ & 1 \\
\hline Juni & - & - \\
\hline Juli & $22.000,00$ & 1 \\
\hline Agustus & $10.621 .000,00$ & 2 \\
\hline September & $22.300,00$ & 1 \\
\hline Oktober & $18.500,00$ & 1 \\
\hline November & - & - \\
\hline Desember & $55.000 .000,00$ & 1 \\
\hline Total & $\mathbf{6 5 . 7 6 0 . 3 0 0 , 0 0}$ & $\mathbf{9}$ \\
\hline
\end{tabular}

(Sumber: PT. XYZ, 2018) 


\section{Usulan Perbaikan Sistem Manajemen Keselamatan dan Kesehatan Kerja (SMK3) sebagai Upaya Meminimalisir Angka Kecelakaan Kerja Menggunakan Metode HAZOP (Studi Kasus: PT. XYZ)}

Dari Tabel 3 bisa dilihat bahwa biaya yang di keluarkan dalam perbulanya sangat berdampak pada perusahaan.Seperti pada bulan Febuari biaya yang dikeluarkan sebesar Rp. 35.000,00 untuk menangani 1 kasus kecelakaan kerja.Pada bulan Maret mengeluarkan biaya sebesar Rp. 21.000,00 untuk menangani 1 kasus kecelakaan kerja.Di bulan Mei biaya yang harus dikeluarkan yaitu sebesar Rp. 20.500,00 untuk menangani 2 kasus kecelakaan kerja.Pada bulan Juli biaya yang dikeluarkan sebesar Rp. 22.000,00 untuk menangani 1 kasus kecelakaan kerja. Kemudian Pada bulan Agustus mengalami peningkatan yang sangat drastis dari bulan sebelumnya karena harus mengeluarkan biaya Rp. 10.621.000,00 untuk menangani 2 kasus kecelakaan kerja. Pada bulan September biaya yang dikeluarkan sebesar Rp. 22.300,00, bulan Oktober biaya yang dikeluarkan sebesar Rp. 18.500,00. Di bulan Desember mengalami peningkatan kembali biaya yang dikeluarkan sebesar Rp. 55.000.000,00untuk menangani 1 kasus kecelakaan kerja. Oleh sebab itu untuk meminimalisir kecelakaan kerja yang ada pada perusahaan perlu adannya perbaikan dalam cara kerja maupun dalam area produksi.

Dari permasalahan tersebut perlu dilakukan penelitian untuk mengetahui potensi bahaya serta dampak dari terjadinya kecelakaan kerja yang terjadi di PT. XYZ. Metode yang digunakan adalah Hazard and Operability Study (HAZOP) yaitu bentuk pencegahan terhadap segala kemungkinan bahaya yang terjadi sehingga proses yang berlangsung pada suatu sistem dapat berjalan dengan lancar dan aman (Pujiono, 2013).

\section{Metode}

Dalam penelitian ini adapun langkah-langkah untuk identifikasi hazard dengan menggunakan metode HAZOP worksheet dan Risk Assessment. Pertama Mengetahui urutan proses yang ada pada area penelitian. Kedua mengidentifikasi hazard yang ditemukan pada area penelitian. Ketiga melengkapi kriteria yang ada pada HAZOP worksheet dengan urutan sebagai berikut: mengklasifikasikan hazard yang ditemukan. Mendeskripsikan deviation atau penyimpangan yang terjadi selama proses operasi. Mendeskripsikan penyebab terjadinya penyimpangan (Cause). Mendeskripsikan apa yang ditimbulkan dari penyimpangan tersebut (Consequence). Menentukan Action atau tindakan sementara yang dapat dilakukan. Menilai resiko atau Risk Matrix yang timbul dengan mengidentifikasikan kriteria likelihood yang digunakan adalah frekuensi dimana dalam perhitungannya secara kuantitatif berdasarkan data atau record perusahaan selama kurun waktu tertentu Kriteria consequence (severity) yang digunakan adalah akibat apa yang akan diterima pekerja yang didefinisikan secara kualitatif dan mempertimbangkan hari kerja yang hilang.

Metode HAZOP digunakan dalam menyelesaikan masalah dalam penelitian ini karena metode HAZOP bisa digunakan untuk mengidentifikasi risiko yang terkait dengan operasi dan pemeliharaan sistem, mengidentifikasi masalah potensial operabilitas dan penyebab gangguan operasional serta kemungkinan penyimpangan pada produk yang mengarah pada ketidaksesuaian produk pada PT. XYZ tersebut. Sehingga metode HAZOP sangat sesuai digunakan dalam penyelesaian masalah K3 di PT. XYZ.

\section{Hasil dan Pembahasan}

Berdasarkan hasil wawancara yang dilakukan oleh peneliti kepada pihak SHE, operator mesin, serta pihak maintenance diketahui bahwa sumber bahaya yang terdapat pada divisi mesin adalah berasal dari material bahan bakar yang panas, debu batubara, air dan uap yang dihasilkan mesin, listrik bertekanan tinggi serta jatuh dari ketinggian karena design mesin di perusahaan ini sangat besar dan tinggi konstruksinya, jadi kemungkinan pekerja untuk terjatuh selalu ada. Lalu kebisingan dari alat mesin serta radiasi panas merupakan sumber bahaya yang terdapat pada divisi mesin ini. Jenis bahaya pada lingkungan kerja dalam mesin terdapat empat jenis bahaya diantaranya adalah bahaya fisik, bahaya mekanis, bahaya kimia dan bahaya listrik. 
Usulan Perbaikan Sistem Manajemen Keselamatan dan Kesehatan Kerja (SMK3) sebagai Upaya Meminimalisir Angka Kecelakaan Kerja Menggunakan Metode HAZOP (Studi Kasus: PT. XYZ)

Bahaya fisik terdapat pada pekerjaan yang efek bahayanya berdampak kepada pekerja baik secara langsung (tersembur material panas dan uap panas) atau berdaya jangka waktu (gangguan pendengaran akibat kebisingan). Bahaya mekanis bersumber dari peralatan mekanis atau benda-benda yang dikerjakan oleh pekerja (terjepit blower). Bahaya kimia bersumber dari bahan-bahan atau zat kimia. Dan bahaya listrik yang dapat mengakibatkan berbagai bahaya seperti kebakaran, sengatan listrik dan korsleting. Risiko merupakan perwujudan profesi yang mengakibatkan kemungkinan kerugian menjadi lebih besar.

Dalam pekerjaan di divisi mesin terdapat beberapa potensi bahaya yang berakibat risiko. Bermacammacam risiko yang terdapat pada di lingkungan kerja pada divisi mesin diantaranya adalah terjepit, terjatuh dari ketinggian, luka bakar, gangguan pendengaran, kebisingan, tersengat listrikdan lain-lain. Observasi pada tahap ini dibuat untuk mengidentifikasi bahaya risiko pada divisi mesin agar bisa mengetahui dan menilai risikonya serta dapat menganalisa kegiatanya prosesnya dilaksankan secara rutin dan tidak rutin atau darurat dan mengetahui bahaya tersebut penting atau tidaknya dalam pandangan pihak pihak terkait. Berikut tabel hasil observasi yang di buat terkait tindakan identifikasi bahaya pada divisi mesin. Tabel 4 menunjukkan hasil identifikasi hazard and risk.

Tabel 4: Identifikasi Hazard And Risk

\begin{tabular}{|c|c|c|c|}
\hline No & Proses & Uraian Temuan Hazard & Risiko \\
\hline 1 & Loading Ramp & $\begin{array}{l}\text { Memindahkan TBS dari } \\
\text { tempat penerimaan buah } \\
\text { sementara kedalam lori } \\
\text { perebusan }\end{array}$ & $\begin{array}{l}\text { 1. Terjatuh dari Ketinggian } \\
\text { 2. Tertimpa TBS } \\
\text { 3. Terkena Gancu } \\
\text { 4. Tergelincir/Jatuh } \\
\text { 5. Terjepit Sambungan Lori }\end{array}$ \\
\hline 2 & Sterilizer & Tempat perebusan TBS & $\begin{array}{l}\text { 1. Uap Panas } \\
\text { 2. Kebisingan } \\
\text { 3. Kebocoran pada drum } \\
\text { 4. Terjepit } \\
\text { 5. Tergelincir/Terjatuh }\end{array}$ \\
\hline 3. & Tippler(Pembanting) & $\begin{array}{l}\text { Pemisah Brondolan dengan } \\
\text { Janjang Kosong }\end{array}$ & $\begin{array}{l}\text { 1. Kejatuhan roli } \\
\text { 2. Kebisingan } \\
\text { 3. Tergelincir/Jatuh } \\
\text { 4. Tertimpa TBS } \\
\text { 5. Terkena Hempasan Brondol }\end{array}$ \\
\hline 4 & Digester & $\begin{array}{l}\text { Untuk melumatkan brondolan } \\
\text { sehingga daging buah terpisah } \\
\text { dari bijinya }\end{array}$ & $\begin{array}{l}\text { 1. Panas } \\
\text { 2. Kebisingan } \\
\text { 3. Luka Bakar } \\
\text { 4. Gangguan Pernafasan } \\
\text { 5. Luka Melepuh }\end{array}$ \\
\hline 5 & Press & $\begin{array}{l}\text { Untuk memeras minyak dari } \\
\text { daging buah }\end{array}$ & $\begin{array}{l}\text { 1. Panas } \\
\text { 2. Terjatuh dari Ketinggian } \\
\text { 3. Kebisingan } \\
\text { 4. Luka Bakar } \\
\text { 5. Gangguan Pernafasan } \\
\text { 6. Luka Melepuh }\end{array}$ \\
\hline 6 & Klarifikasi & $\begin{array}{l}\text { Untuk memisahkan antara } \\
\text { minyak dengan air dan kotoran } \\
\text { yang masih ada sehingga } \\
\text { menghasilkan minyak murni }\end{array}$ & $\begin{array}{l}\text { 1. Terkena Minyak Panas } \\
\text { 2. Terjatuh dari Ketinggian } \\
\text { 3. Terbentur Saluran Pipa } \\
\text { 4. Terkena Uap Panas }\end{array}$ \\
\hline
\end{tabular}


Usulan Perbaikan Sistem Manajemen Keselamatan dan Kesehatan Kerja (SMK3) sebagai Upaya Meminimalisir Angka Kecelakaan Kerja Menggunakan Metode HAZOP (Studi Kasus: PT. XYZ)

\begin{tabular}{|c|c|c|c|}
\hline 7 & Kernel & $\begin{array}{l}\text { Tempat penimbunan, } \\
\text { pengeringan dan penyimpanan } \\
\text { karnel produksi sebelum } \\
\text { dikirim ke konsumen }\end{array}$ & $\begin{array}{l}\text { 1. Luka Cidera } \\
\text { 2. Panas } \\
\text { 3. Tergelincir/Jatuh } \\
\text { 4. Kebisingan } \\
\text { 5. Dermatisi Kontak } \\
\text { 6. Gangguan Pernafasan }\end{array}$ \\
\hline 8 & Boiler & $\begin{array}{l}\text { Penghasil Stem atau disebut } \\
\text { jantung pabrik }\end{array}$ & $\begin{array}{l}\text { 1. Panas } \\
\text { 2. Kebakaran dan Ledakan } \\
\text { 3. Kebisingan } \\
\text { 4. Luka Bakar } \\
\text { 5. Tergelincir/Terbentur } \\
\text { 6. Kesetrum }\end{array}$ \\
\hline
\end{tabular}

(Sumber: PT. XYZ, 2018)

Setelah melakukan identifikasi hazard and risk seperti pada Tabel 4., maka selanjutnya dilakukan penilaian resiko dengan memperhatikan kriteria tingkat keparahan seperti pada Tabel 5, kriteria sebagai berikut : 1. Likelihood (L) adalah Adalah kemungkinan terjadinya konsekuensi dengan sistem pengaman yang ada. (tabel 5). 2. Consequences (C) merupakan tingkat keparahan yang diperkirakan dapat terjadi (Pujiono, 2013).

Tabel 5: Hasil Kriteria Likelihood

\begin{tabular}{|c|c|c|}
\hline \multirow[t]{2}{*}{ Level Criteria } & \multicolumn{2}{|l|}{ Description } \\
\hline & Kualitatif & Semi Kualitatis \\
\hline $\begin{array}{l}\text { Jarang } \\
\text { Terjadi }\end{array}$ & $\begin{array}{c}\text { Dapat dipikirkan tetapi tidak hanya saat } \\
\text { keadaan ekstrim }\end{array}$ & $\begin{array}{c}\text { Kurang dari } 1 \text { kali dalam } 10 \\
\text { Tahun }\end{array}$ \\
\hline $\begin{array}{l}\text { Kemungkinan } \\
\text { Terjadi }\end{array}$ & $\begin{array}{l}\text { Belum terjadi tetapi bisa muncul/terjadi pada } \\
\text { suatu waktu }\end{array}$ & Terjadi 1 kali per 10 tahun \\
\hline Mungkin & $\begin{array}{l}\text { Seharusnya terjadi dan mungkin telah } \\
\text { menjadi/muncul disini atau ditempat lain }\end{array}$ & $\begin{array}{l}1 \text { kali per } 5 \text { tahun sampai } 1 \text { kali } \\
\text { pertahun }\end{array}$ \\
\hline$\underset{\text { Besar }}{\text { Kemungkinan }}$ & $\begin{array}{c}\text { Dapat terjadi dengan mudah, mungkin } \\
\text { muncul dalam keadaan yang paling } \\
\text { banyakTerjadi }\end{array}$ & $\begin{array}{l}1 \text { kali per } 5 \text { tahun sampai } 1 \text { kali } \\
\text { pertahun }\end{array}$ \\
\hline Hampir Pasti & $\begin{array}{l}\text { Sering terjadi, diharapkan muncul dalam } \\
\text { keadaan yang paling banyak terjadi }\end{array}$ & Lebih dari 1 kali per bulan \\
\hline
\end{tabular}

Setelah dilakukan penilaian resiko dengan memperhatikan kriteria tingkat keparahan seperti pada Tabel 5, maka selanjutnya didapatkan hasil kriteria consequences seperti pada Tabel 6 .

Tabel 6: Hasil Kriteria Consequences

\begin{tabular}{ccc}
\hline Level Uraian & \multicolumn{2}{c}{ Consequences } \\
\cline { 2 - 3 } Tidak & Kualitatif & Description \\
Signifikan & $\begin{array}{c}\text { Kejadian tidak menimbulkan kerugian } \\
\text { ataucidera pada manusia }\end{array}$ & $\begin{array}{c}\text { Tidak menyebabkan kehilangan } \\
\text { hari kerja }\end{array}$ \\
\hline Kecil & $\begin{array}{c}\text { Menimbulkan cidera ringan, kerugian kecildan } \\
\text { tidak menimbulkan dampak serius terhadap } \\
\text { kelangsungan bisnis }\end{array}$ & $\begin{array}{c}\text { Masih dapat bekerja pada hari } \\
\text { atau shift yang sama }\end{array}$ \\
\hline Sedang & $\begin{array}{c}\text { Cedera berat dan dirawat dirumah sakit, } \\
\text { tidakmenimbulkan cacat tetap,kerugian } \\
\text { finansialsedang }\end{array}$ & $\begin{array}{c}\text { Kehilangan hari kerja dibawah 3 } \\
\text { hari }\end{array}$ \\
\hline Berat & $\begin{array}{c}\text { Menimbulkan cidera parah dan cacat tetapdan } \\
\text { kerugian finansial besar sertamenimbulkan }\end{array}$ & $\begin{array}{c}\text { Kehilangan hari kerja 3 hari atau } \\
\text { lebih }\end{array}$ \\
\hline
\end{tabular}


Usulan Perbaikan Sistem Manajemen Keselamatan dan Kesehatan Kerja (SMK3) sebagai Upaya Meminimalisir Angka Kecelakaan Kerja Menggunakan Metode HAZOP (Studi Kasus: PT. XYZ)

dampak serius terhadapkelangsungan usaha
Bencana Mengakibatkan korban meninggal dankerugian Kehilangan hari kerja selamanya parah bahkan dapat menghentikankegiatan usaha selamanya

Setelah menentukan nilai likelihood dan consequences dari masing-masing sumber potensi bahaya, maka langkah selanjutnya adalah mengalikan nilai likelihood dan consequences sehingga diperoleh tingkat bahaya (risk level) pada risk matrix yang mana nantinya akan digunakan dalam melakukan perangkingan terhadap sumber potensi bahaya yang akan dijadikan acuan sebagai rekomendasi perbaikan apa yang sesuai dengan permasalahan yang ada. Penilaian risiko itu sendiri dilakukan dengan menggunakan risk matrix seperti pada Gambar 2.

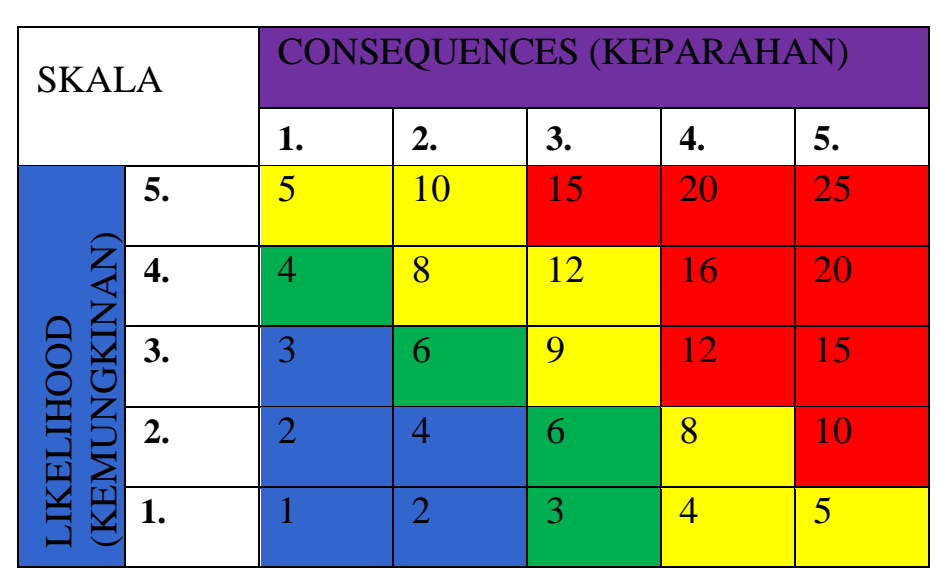

KETERANGAN:

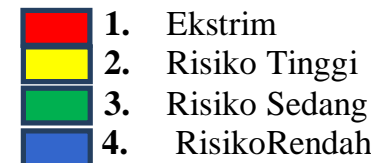

Gambar 2: Risk Matrix

Berdasarkan penelitian yang dilakukan di PT. XYZ dengan menggunakan metode HAZOP, maka didapatkan beberapa temuan potensi bahaya, seperti pada Tabel 7 .

Tabel 7. Temuan Potensi Bahaya (Risk Matrix)

\begin{tabular}{|c|c|c|c|c|c|c|c|}
\hline No & Proses & Risiko & $\begin{array}{l}\text { Sumber } \\
\text { Hazard }\end{array}$ & & $\mathbf{C}$ & $S$ & $\begin{array}{c}\text { Risk } \\
\text { Matrix }\end{array}$ \\
\hline 1 & $\begin{array}{l}\text { Loading } \\
\text { Ramp }\end{array}$ & $\begin{array}{ll}1 & \text { Terjatuh dari Ketinggian } \\
2 & \text { Tertimpa TBS } \\
3 & \text { Terkena Gancu } \\
4 & \text { Tergelincir/Jatuh } \\
5 & \text { Terjepit Sambungan Lori }\end{array}$ & 1. Sikap Pekerja & 2 & 1 & 2 & Rendah \\
\hline 2 & Sterilizer & $\begin{array}{l}\text { 1. Uap Panas } \\
\text { 2. Kebisingan } \\
\text { 3. Kebocoran pada drum } \\
\text { 4. Terjepit } \\
\text { 5. Tergelincir/Terjatuh }\end{array}$ & $\begin{array}{l}\text { 1. Kondisi } \\
\text { Lingkungan Kerja } \\
\text { 2. Sikap Pekerja }\end{array}$ & 3 & 2 & 6 & Sedang \\
\hline 3. & Tippler & $\begin{array}{l}\text { 1. Kejatuhan roli } \\
\text { 2. Kebisingan } \\
\text { 3. Tergelincir/Jatuh } \\
\text { 4. Tertimpa TBS } \\
\text { 5. Terkena Hempasan } \\
\text { Brondol }\end{array}$ & $\begin{array}{l}\text { 1. Kondisi } \\
\text { Lingkungan Kerja } \\
\text { 2. Sikap Pekerja }\end{array}$ & 3 & 2 & 6 & Sedang \\
\hline 4 & Digester & $\begin{array}{l}\text { 1. Panas } \\
\text { 2. Kebisingan } \\
\text { 3. Luka Bakar }\end{array}$ & $\begin{array}{ll}\text { 1. } & \text { Sikap Pekerja } \\
\text { 2. Kondisi } \\
\text { Lingkungan }\end{array}$ & 3 & 3 & 9 & Tinggi \\
\hline
\end{tabular}


Usulan Perbaikan Sistem Manajemen Keselamatan dan Kesehatan Kerja (SMK3) sebagai Upaya Meminimalisir Angka Kecelakaan Kerja Menggunakan Metode HAZOP (Studi Kasus: PT. XYZ)

\begin{tabular}{|c|c|c|c|c|c|c|c|}
\hline & & $\begin{array}{l}\text { 4. Gangguan Pernafasan } \\
\text { 5. Luka Melepuh }\end{array}$ & $\begin{array}{ll} & \text { Kerja } \\
\text { 3. Uap panas } \\
\text { 4. } & \text { Peralatan Panas }\end{array}$ & & & & \\
\hline 5 & Press & $\begin{array}{l}\text { 1. Panas } \\
\text { 2. Terjatuh dari Ketinggian } \\
\text { 3. Kebisingan } \\
\text { 4. Luka Bakar } \\
\text { 5. Gangguan Pernafasan } \\
\text { 6. Luka Melepuh }\end{array}$ & $\begin{array}{l}\text { 1. Kondisi } \\
\text { Lingkungan Kerja } \\
\text { 2. Uap panas } \\
\text { 3. Penggunaan APD } \\
\text { tidak Disiplin } \\
\text { 4. Peralatan Panas }\end{array}$ & 3 & 3 & 9 & Tinggi \\
\hline 6 & Klarifikasi & $\begin{array}{l}\text { 1. Terkena Minyak Panas } \\
\text { 2. Terjatuh dari Ketinggian } \\
\text { 3. Terbentur Saluran Pipa } \\
\text { Terkena Uap Panas }\end{array}$ & $\begin{array}{l}\text { 1. Kondisi } \\
\text { Lingkungan Kerja }\end{array}$ & 4 & 4 & 16 & Ekstrim \\
\hline 7 & Kernel & $\begin{array}{l}\text { 1. Luka Cidera } \\
\text { 2. Panas } \\
\text { 3. Tergelincir/Jatuh } \\
\text { 4. Kebisingan } \\
\text { 5. Dermatisi Kontak } \\
\text { 6. Gangguan Pernafasan }\end{array}$ & $\begin{array}{l}\text { 1. Sikap Pekerja } \\
\text { 2. Kondisi } \\
\text { Lingkungan Kerja } \\
\text { 3. Tidak } \\
\text { menggunakan APD } \\
\text { 4. Penumpukan } \\
\text { Bahan Kimia }\end{array}$ & 3 & 4 & 12 & Ekstrim \\
\hline 8 & Boiler & $\begin{array}{l}\text { 1. Panas } \\
\text { 2. Kebakaran dan Ledakan } \\
\text { 3. Kebisingan } \\
\text { 4. Luka Bakar } \\
\text { 5. Tergelincir/Terbentur } \\
\text { 6. Kesetrum }\end{array}$ & $\begin{array}{l}\text { 1. Kondisi } \\
\text { Lingkungan Kerja } \\
\text { 2. Temperatur Tinggi }\end{array}$ & 5 & 4 & 20 & Ektrim \\
\hline
\end{tabular}

Dari risk matrix di atas kemudian dapat dihitung skor resiko dan prioritas untuk melakukan tindakan perbaikan. Untuk menghitung skor resiko adalah sebagai berikut:

$$
\text { Resiko }=\text { Kemungkinan } \mathrm{x} \text { Keparahan }
$$

Resiko bahaya yang ditimbulkan pada area proses produksi pengaman antara lain adalah:

1. Resiko ekstrim, yaitu pada area Stasiun Klarifikasi, Stasiun Kernel dan Stasiun Boiler dengan uraian resiko, sebagai berikut:
a. Kebakaran dan Ledakan
b. Kebisingan
c. Luka Bakar
d. Tergelincir/Terbentur
e. Terkena Minyak Panas
f. Terjatuh dari Ketinggian
g. Terkena Uap Panas

2. Resiko tinggi seperti pada Stasiun Digester dan Stasiun Pressdengan uraian resiko, sebagai berikut:
a. Tertimpa TBS dan lori.
b. Tergelincir/terjatuh karena lantai licin.
c. Terkena hempasan berondolan.
d. Gangguan pernafasan akibat udara terkena bahan kimia yang berbahaya.
e. Gangguan kesehatan pendengaran dan salah dalam menangkap komunikasi.
f. Luka melepuh maupun luka bakar.
g. Heat exhausting.

3. Resiko sedang, yaitu pada Stasiun Sterilizer dan Stasiun Tippler (Pembanting) dengan uraian resiko sebagai berikut:

a. Kejatuhan roli 
Usulan Perbaikan Sistem Manajemen Keselamatan dan Kesehatan Kerja (SMK3) sebagai Upaya Meminimalisir Angka Kecelakaan Kerja Menggunakan Metode HAZOP (Studi Kasus: PT. XYZ)

b. Kebisingan

c. Tergelincir/Jatuh

d. Tertimpa TBS

e. Terkena Hempasan Brondol

f. Uap Panas

g. Kebocoran pada drum

4. Resiko rendah, yaitu pada Stasiun Loading Ramp dengan uraian risiko sebagai berikut:
a. Tangan terjepit pengunci bak, jembatan penyambung dan sambungan lori.
b. Tertimpa TBS, terkena gancu.
c. Tergelincir/terjatuh dan terjepit sambungan lori.
d. Terkena semburan uap panas.
e. Kebisingan.

Tabel 8 menunjukkan bahwa Risk Level yang paling menonjol yaitu Resiko Ekstrim. Hasil dari data di atas dapat dilihat pada Gambar 3:

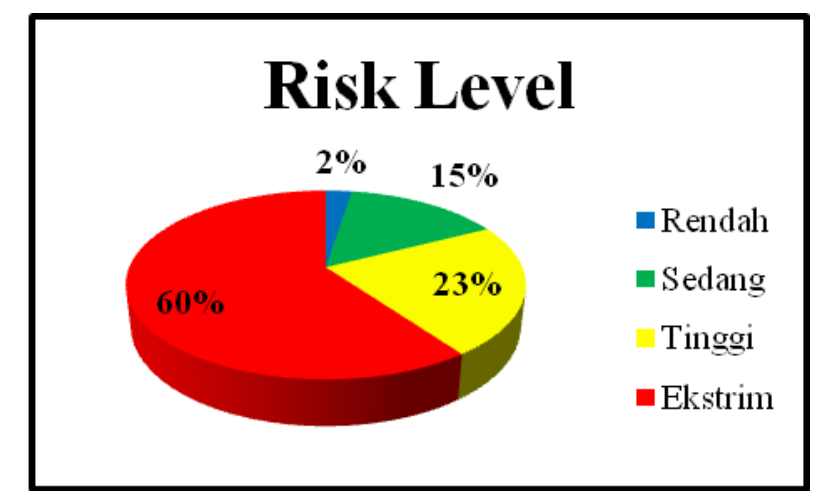

Gambar 3:Diagram Risk Matrix

Dari Gambar 3 maka dapat dilihat potensi bahaya kerja ekstrim sebanyak 60\% dan resiko tinggi 23\%, resiko sedang sebanyak $15 \%$ dan resiko rendah $2 \%$. Dari sumber bahaya dalam tahapan penilaian resiko maka tindakan selanjutnya adalah HAZOP Worksheet, untuk memberikan ide-ide dalam dalam mengurangi resiko kecelakaan kerjaan yang terjadi dilakukan pengendalian atau usulan perbaikan untuk mengurangi tingkatan kecelakaan kerja di PT. XYZ yang dilihat dari tingkat bahaya yang paling tinggi atau berada pada kategori ekstrim.

Pada penelitian ini yang dianalisis dan diusulkan tindakan perbaikan hanya pada tingkat resiko yang ekstrim karena tingkat resiko inilah yang sering terjadi dan mempunyai nilai resiko yang sangat tinggi dibandingkan dengan jenis resiko yang lainnya. Sumber bahaya kecelakaan kerja pada kategori ekstrim berada pada sumber bahaya stasiun Klarifikasi Kernel dan Boiler. HAZOP Worksheet dalam mengurangi resiko kecelakaan kerja yang terjadi pada PT. XZY dengan worksheet yang di usulkan seperti pada Tabel 8.

Tabel 8. HAZOP Worksheet

\begin{tabular}{|c|c|c|c|c|}
\hline No & Proses & Risiko & $\begin{array}{l}\text { Sumber } \\
\text { Hazard }\end{array}$ & Tindakan \\
\hline 1 & Klarifikasi & $\begin{array}{l}\text { 1. Terkena Minyak Panas } \\
\text { 2. Terjatuh dari } \\
\text { Ketinggian } \\
\text { 3. Terbentur Saluran Pipa } \\
\text { 4. Terkena Uap Panas }\end{array}$ & $\begin{array}{l}\text { Kondisi Lingkungan } \\
\text { Kerja }\end{array}$ & $\begin{array}{l}\text { Memakai APD } \\
\text { (Sarung Tangan, } \\
\text { Masker, Safety Boot, } \\
\text { Kaca Mata, Helm) } \\
\text { Pagar Pengaman }\end{array}$ \\
\hline 2 & Kernel & $\begin{array}{l}\text { 1. Luka Cidera } \\
\text { 2. Panas }\end{array}$ & $\begin{array}{l}\text { 1. Sikap Pekerja } \\
\text { 2. Kondisi }\end{array}$ & $\begin{array}{l}\text { Administrasi dan } \\
\text { APD (Sarung }\end{array}$ \\
\hline
\end{tabular}


Usulan Perbaikan Sistem Manajemen Keselamatan dan Kesehatan Kerja (SMK3) sebagai Upaya Meminimalisir Angka Kecelakaan Kerja Menggunakan Metode HAZOP (Studi Kasus: PT. XYZ)

\begin{tabular}{|c|c|c|c|}
\hline & $\begin{array}{l}\text { 3. Tergelincir/Jatuh } \\
\text { 4. Kebisingan } \\
\text { 5. Dermatisi Kontak } \\
\text { 6. Gangguan Pernafasan }\end{array}$ & $\begin{array}{l}\text { Lingkungan Kerja } \\
\text { 3. Tidak } \\
\text { menggunakan APD } \\
\text { 4. Penumpukan Bahan } \\
\text { Kimia }\end{array}$ & $\begin{array}{l}\text { Tangan,Earplug, } \\
\text { Masker, Safty Boot) }\end{array}$ \\
\hline Boiler & $\begin{array}{l}\text { 1. Panas } \\
\text { 2. Kebakaran dan Ledakan } \\
\text { 3. Kebisingan } \\
\text { 4. Luka Bakar } \\
\text { 5. Tergelincir/Terbentur } \\
\text { 6. Kesetrum }\end{array}$ & $\begin{array}{l}\text { 1. Kondisi } \\
\text { Lingkungan Kerja } \\
\text { 2. Temperatur Tinggi }\end{array}$ & $\begin{array}{l}\text { Memperhatikan } \\
\text { Keselamatan Kerja } \\
\text { Menggunakan APD } \\
\text { (Ear Muff, Sepatu } \\
\text { Safty, Google Boiler, } \\
\text { Helm) }\end{array}$ \\
\hline
\end{tabular}

\section{Kesimpulan}

Dari pengolahan data dan analisa yang telah dilakukan terdapat dua jenis kecelakaan kerja pada PT. XYZ, yaitu kecelakaan kerja ringan dan berat.Jenis resiko bahaya yang ditimbulkan berdasarkan Matrik Resiko (Risk Matrix) potensi bahaya kerja ekstrim sebanyak 60\% yaitu pada Stasiun Kernal, Stasiun Klarifikasi dan Stasiun Boiler. Resiko tinggi 23\% adalah Stasiun Digester dan Stasiun Press.Resiko sedang sebanyak $15 \%$ terdapat pada Stasiun Sterilizer dan Stasiun Tippler (Pembanting).Resiko rendah 2\% yaitu Stasiun Loading Ramp.Usulan perbaikan SMK3 di PT. XYZ sebagai berikut:Perusahaan harus lebih mengawasi kepada para pekerja yang melanggar peraturan keselamatan kerja dalam penggunaan APD dan selalu memperingatkan pekerja untuk lebih berhatihati selama bekerja.Perusahaan dapat memperhatikan penerapan K3 yang baik bagi pekerjaan agar tidak terjadi hal-hal yang dapat menimbulkan risiko yang sangat tinggi.Perusahaan dapat melakukan pemeriksaan yang rutin terhadap pekerja, alat dan berbagai hal yang menyangkut Kesehatan dan Keselamatan Kerja (K3).Pekerja dapat mengikuti setiap intruksi ataupun aturan yang diterapkan oleh pihak managemen secara berkesinambungan sehingga target zero accident dapat tercapai.

\section{Daftar Pustaka}

Nur, Muhammad dan Al, Anshari. 2015. Analisis Keselamatan Dan Kesehatan Kerja Terhadap Kinerja Karyawan PT. Johan Sentosa (PKS-Bangkinang). UIN Sultan Syarif Kasim Riau. [Online] Available http://ejournal.uin-suska.ac.id/index.php/jti/article/view/6320, diakses 13 September. 2019.

Nur, Muhammad dan Chania, D., O. 2016.Pengaruh Pelaksanaan Program Keselamatan dan Kesehatan Kerja (K3) terhadap Produktivitas Kerja Karyawan pada PT. Bormindo Nusantara Duri. UIN Sultan Syarif Kasim Riau. [Online] Available http://ejournal.uinsuska.ac.id/index.php/jit/article/view/5576, diakses 13 September. 2019.

Nuraini, Linda dan Ratih, S., W. Kepatuhan Terhadap Peraturan Keselamatan dan Kesehatan Kerja (K3) Hubungannya dengan Kecelakaan Kerja.Universitas Muhammadiyah Semarang. [Online] Available https://jurnal.unimus.ac.id, diakses 19 September. 2019.

Pujiono, B, N., Ishardita, P, T. Dan Remba, Y, E. 2013. Analisis Potensi Bahaya Serta Rekomendasi Perbaikan Dengan Metode Hazard And Operability Study (Hazop) Melalui Perangkingan Ohs Risk Assessment And Control. Malang. Universitas Brawijaya. [Online] Available http://journals.ums.ac.id/index.php/jiti/ article/view/621, diakses 16 September. 2019.

Rudyarti, E. 2017.Hubungan Pengetahuan Keselamatan Dan Kesehatan Kerja Dan Sikap Penggunaan Alat Pelindung Diri Dengan Kejadian Kecelakaan Kerja Pada Pengrajin Pisau Batik Di PT. X. Universitas Darussalam Gontor. [Online] Available http://semnask3.fk.uns.ac.id/wp-content/ uploads/2017/05/PROSIDING-SEMNAS-K31.pdf\#page=21, diakses 10 Maret. 2019. 